ORIGINAL ARTICLE

\title{
Radiological and Functional Outcomes of Hybrid External Fixator Treated Schatzker Type V-Vi Tibial Plateau Fractures
}

\author{
USMAN AMJAD ${ }^{1}$, ANUM SATTAR ${ }^{2}$, KIRAN ZARNAB KHALID², MUHAMMAD ABDUL SHAKOOR ${ }^{4}$, WALEED IMTIAZ ${ }^{5}$, SYED WASIF ALI \\ $\mathrm{SHAH}^{6}$ \\ ${ }^{1}$ Consultant Orthopaedic Surgeon, ${ }^{2,3}$ WMO, ${ }^{4,5}$ Registrar, ${ }^{6}$ Associate Professor of Orthopaedic Surgery \\ Department of Orthopaedic Surgery, Shaikh Zayed Hospital, Lahore \\ Correspondence to Dr. Usman Amjad, Email:drusmanamjad@outlook.com, Mob: 0332-6798682,
}

\begin{abstract}
Background: Complex proximal tibial fractures caused by high energy trauma classified as Schatzker type $\mathrm{V}$ and $\mathrm{VI}$ pose a management challenge due to associated extensive soft tissue damage.Though open reduction and dual plating is considered a gold standard treatment option in these fractures but associated with wound breakdown and infection.

Aim: To evaluate the radiological and functional outcomes of percutaneous hybrid fixator as alternative treatment option in these fractures.

Methodology: This study designed as prospective case series was conducted in Sheikh Zayed Hospital Lahore between May 2019 to May 2021.Twenty four patients fulfilling the inclusion criteria were operated using a hybrid external fixator in schatzkerV and VI tibial plateu fractures with compromised soft tissue.On follow upradiological and functional outcomes were being evaluated.

Results: At Six months follow up after surgery Rasmussen knee score was graded as excellent in 13, good in 8 , fair in 3 and poor in 0 patients. In radiological outcome mean time to bony union was 13.5 weeks. One case of varus malunion and no case case of non union was observed in our study.

Conclusion: Hybrid external fixator is a well found fixation alternative as compared to conventional open reduction and internal fixation in Complex tibial plateau fractures with extensive soft tissue disruption achieving satisfactory radiological and functional outcomes.
\end{abstract}

Keywords: Schatzker, Tibial plateau, Hybrid fixator.

\section{INTODUCTION}

Tibial plateau fractures are complex intra-articular fractures that comprise of about $1 \%$ of all fractures in adults and $8 \%$ in elderly. ${ }^{1}$ The incidence of this fracture is on a rise with the increasing incidence of road traffic accidents and high velocity injuries. The mechanism of injury is axial loading combined with torsional forces that lead to disruption of articular geometery and comminution of metaphysis along with condylar depression as well. ${ }^{2}$ Schatzker classified these fractures into six types. Of these Schatzker type V, fractures involving both condyles and Schatzker VI ,those with meta-diaphyseal disruption are most difficult fractures to treat as associated extensive soft tissue damage posing a challenge to orthopedic surgeon regarding restoration of articular alignment by addressing condylar depressions and in addition, the preservation of soft tissue envelope. ${ }^{3}$

Standard radiographic imaging includes antero-posterior and lateral views. The CT scan is becoming more popular in the evaluation of articular fragments orientation, comminution and allowing preoperative planning facilitating fracture reduction, especially for the minimally invasive techniques of treatment. ${ }^{4} \mathrm{~A}$ lot of treatment modalities are being offered for these complex high energy fractures over the years that range from simple traction to challenging surgeries. Though considered gold standard, plating as mode of open reduction and internal fixation provides adequate reduction of articular geometery and stability but further disrupt the already compromised soft-tissue envelope which leads to wound dehiscence and burdensome rates of infection..$^{5-6}$ The utilization of hybrid external fixator in the management of Schatzker V and VI tibial fractures may provide acceptable reduction results without jeopardizing the soft-tissue elements. In this external fixator, condyles are stabilized with tensioned wires and a ilizarov ring with or without additional percutaneous screws fixation as necessary, and the construct is connected to a monolateral pin fixator on the shaft. This assembly not only permits early joint mobilization but allows joint remodeling and cartilage to regenerate..$^{7-9}$

In our study we assessed radiological outcomes and functional outcomes of hybrid fixator as definitive treatment option

Received on 11-04-2021

Accepted on 24-08-2021 in Schatzker type V and VI tibial fractures with compromised soft tissue.

\section{MATERIALS AND METHODS}

The study was a prospective design case series and was conducted in Orthopedic Department of Shaikh Zayed Hospital Lahore for a period of 2 years from May 2019 to May 2021. Approval from the institutional ethics committee was sought beforehand. A total of 24 patients were treated with hybrid fixator. All patients above the age of 18 years with Schatzker type $V$ and VI fractures who gave informed consent for surgery and follow-up were included while patients with contralateral lower limb fractures, ipsilateral floating knee, associated neurovascular injury were excluded from our study. Clinical and radiological assessment was done at the time of admission for all patients.

Above all, the evaluation of the extent of soft tissue compromise and the neurovascular status assessment was done at first examination. In patients who present with gross soft tissue swelling, limb elevation and icing was started immediately along with non-steroidal anti-inflammatory drugs. Anteroposterior and lateral view xray of the affected knee was taken. 3D CT scans were done in few of comminuted fractures that were helpful in pre operative planning of surgical fixation. All fractures were classified with Schatzkers classification and documentation was made. Sample for baseline lab. investigations were then sent for and pre operative anaesthetic clearance was sought and informed consent was taken for surgery and research participation.

Single pre-operative dose of intravenous antibiotics was given 30 minutes before induction of anaesthesia and was continued for five to seven days post-operatively. Image intensifier guided fixation of all fractures was done in spinal anesthesia. Fractures were reduced using traction table and percutneouly with help of schanz screws. Minimal internal fixation with single cancellous screw was achieved prior to fixator application in five patients. Two wires of $2 \mathrm{~mm}$ wire were passed from posterolateral to anteromedial tibia and posteromedial to anterolateral tibia respectively at a safe distance of $14 \mathrm{~mm}$ from the joint line.A separating angle of 60 degree was maintained between the both wires. The wire was then tensioned in the standard manner and a $5 / 8$ th ring was attached to it.The wires were tensioned to $100 \mathrm{~kg}$ 
and wrench tightening ofwire fixation bolts was done held by $3 / 4$ th ilizarov ring with two finger breadth of soft tissue clearance.Two schanz screws of $5 \mathrm{~mm}$ were applied to distal fragment.A carbon fibre rod was used to connect the ilizarov half ring to clamps on schanz screws. All patient were operated by same surgical team.

The patients were on regular follow up post-operatively. $X$ rays were taken in immediate postoperative period, then sequentially at 4 weeks, 2 months, 4 months and at 6 months. Isometeric exercises were started on first post-operative day. Protected weight-bearing was allowed at 4 th week and full weight bearing was allowed after achieving radiological union. Patients were instructed to take care of pin sites with regular antiseptic dressings. Rasmussen score was used for functional grading and radiological outcome in term of mean union time was assessed along with complications such as malunion and pin site infection. The data was analysed using statistical analysis programme (SPSS Version 22). P value of less than 0.05 was considered statistically significant.

\section{RESULTS}

Out of 24 patients in our study, there was male dominance with 16 patients being male and 8 female patients. Age of the patients ranged from 26 to 65 years with mean of 40.95 years. There was tendency for right side affected more than the left as right leg involvement was seen in 15 patients and left sided involvement in 9 patients. Regarding fracture class,there was equal distribution between Schatzker V and VI type with 12 persons in each group. Out of the 24 patients in our study, 20 patients had closed fractures in which 14 patients with $\mathrm{C} 2$ and 6 patients with Tscherne type C3 soft tissue injury. Four patients had compound fractures in which one patient had Gustillo and Anderson grade III injury who underwent wound debridement, followed by the hybrid external fixator application and rest of three patients were of grade II.

The time taken from admission to surgical procedure ranged from one to five days. The time taken by patients to bear weight was ranging from 6 to 10 weeks with average of 8 weeks. The mean ROM of knee was 0 to $110^{\circ}$. According to Rasmussens functional grading, excellent results were seen in 13 patients $(54.16 \%)$, good results in $8(33.33 \%)$, fair in $3(12.5 \%)$ and no patient with poor results seen. In radiological outcome, mean fusion time was 13.5 weeks with range from 11 to 16 weeks and there was no case of bony non union. There was one case of 12 degree varus malunion but was having acceptable range of motion and no difficulty to bear weight. Superficial pin tract infection was seen in five patients which was resolved with a course of antibiotics. All patients showed satisfaction with their functional outcome and none of patient lost to follow up.

\begin{tabular}{|c|c|c|c|c|c|c|}
\hline Age & Gender & Side & Fracture classification & Fracture type & Union time & Rasmussens score \\
\hline 27 & $\mathrm{M}$ & $\mathrm{L}$ & Type V & Closed & 14 & 28 \\
\hline 31 & $\mathrm{~F}$ & $\mathrm{R}$ & Type VI & Closed & 16 & 23 \\
\hline 38 & $\mathrm{~F}$ & $\mathrm{R}$ & Type VI & Closed & 14 & 27 \\
\hline 47 & $\mathrm{M}$ & $\mathrm{R}$ & Type V & Closed & 12 & 27 \\
\hline 29 & $M$ & $\mathrm{~L}$ & Type VI & Closed & 11 & 21 \\
\hline 56 & $\mathrm{~F}$ & $\mathrm{R}$ & Type VI & Closed & 16 & 29 \\
\hline 65 & $\mathrm{M}$ & $\mathrm{R}$ & Type VI & Closed & 14 & 24 \\
\hline 33 & $\mathrm{~F}$ & $\mathrm{~L}$ & Type V & Compound & 12 & 29 \\
\hline 46 & $\mathrm{M}$ & $\mathrm{R}$ & Type V & Closed & 12 & 28 \\
\hline 53 & $\mathrm{M}$ & $\mathrm{L}$ & Type VI & Compound & 14 & 28 \\
\hline 26 & $M$ & $\mathrm{~L}$ & Type V & Closed & 14 & 24 \\
\hline 30 & $\mathrm{M}$ & $\mathrm{R}$ & Type VI & Closed & 16 & 28 \\
\hline 35 & $\mathrm{~F}$ & $\mathrm{R}$ & Type VI & Closed & 12 & 25 \\
\hline 42 & $\mathrm{M}$ & $\mathrm{L}$ & Type V & Closed & 14 & 27 \\
\hline 58 & $\mathrm{M}$ & $\mathrm{R}$ & Type VI & Closed & 14 & 28 \\
\hline 30 & $\mathrm{~F}$ & $\mathrm{R}$ & Type V & Closed & 13 & 19 \\
\hline 36 & $\mathrm{M}$ & $\mathrm{L}$ & Type V & Closed & 11 & 25 \\
\hline 44 & $M$ & $\mathrm{R}$ & Type VI & Closed & 15 & 29 \\
\hline 60 & $\mathrm{~F}$ & $\mathrm{R}$ & Type V & Closed & 14 & 18 \\
\hline 41 & $\mathrm{M}$ & $\mathrm{R}$ & Type V & Compound & 15 & 29 \\
\hline 65 & $M$ & $\mathrm{~L}$ & Type VI & Closed & 13 & 27 \\
\hline 34 & $M$ & $\mathrm{R}$ & Type VI & Closed & 11 & 26 \\
\hline 31 & $\mathrm{~F}$ & $\mathrm{R}$ & Type V & Closed & 15 & 24 \\
\hline 26 & $M$ & $\mathrm{~L}$ & Type V & Compound & 12 & 19 \\
\hline
\end{tabular}

Table 2: Rasmussens functional grading

\begin{tabular}{|l|c|c|}
\hline Functional Grade & No. & \%age \\
\hline Excellent & 13 & 54.16 \\
\cline { 2 - 3 } Good & 8 & 33.33 \\
\cline { 2 - 3 } Fair & 3 & 12.5 \\
\cline { 2 - 3 } & 0 & 0 \\
\hline
\end{tabular}

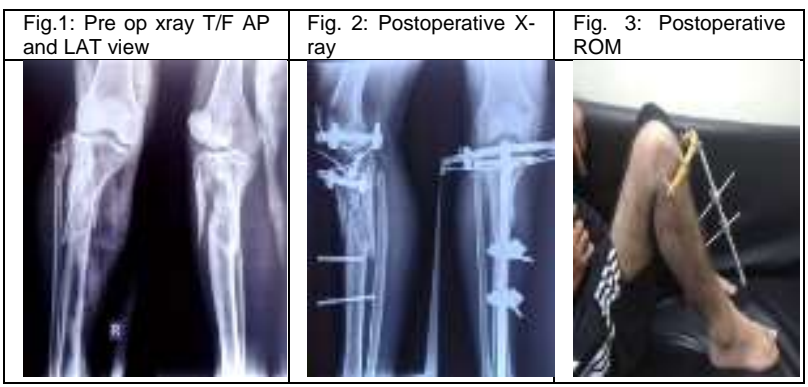

\section{DISCUSSION}

The importance of the soft-tissue envelope in the treatment of tibial plateau fractures has been investigated in the literature and there is an established association of adverse outcomes with severely damaged soft-tissues. ${ }^{10}$ High velocity trauma is being contemplated as a root reason of complications in the management of complex proximal tibial fractures. Many therapies have been prioritized for the management of these complex injuries from simple plaster to minimal internal fixation of fracture with percutaneous screws, open reduction and plating ${ }^{11}$ use of hybrid fixator ${ }^{12}$ or ilizarov ring fixator. ${ }^{13}$

In open reduction and plating, in addition to direct visualization and stable reduction of the articular surface as well as stripping of soft tissue envelope results in serious adverse effects including flap necrosis, wound dehiscence and high infection ultimately jeopardizing the end result. Tscherne et al, compared the results of surgical fixation and conservative treatment of complex proximal tibial fractures and interpreted outcome as progressive mobility, reduced malunion percentage and $5 \%$ 
revision rate for the patients undergoing surgical fixation. ${ }^{14}$ Stevens et al, reported several surgical complications and functional issues post operatively ${ }^{15}$, while Young and Barrack presented the results of case series of bicondylar plating for complex tibial plateau fractures with highest infection rate of $88 \% .^{16,17}$ Jiang et al compared locking plates to buttress plates for fixation of tibial plateau fractures in their prospective study and interpretation of similar outcome for the both groups was made. ${ }^{18}$ Higgins et al compared the outcomes of tibial plateu fractures stabilized by single lateral locking plate to dual plating and reported increased rates of subsidence in locking plate group ${ }^{19}$.

Though literature supports the use of percutaneous hybrid fixator as a definitive mode of management but still certain authors advocate this method of treatment as a provisional mean of fixation. With the development of ilizarov and hybrid frames have given new prospect to treatment of complex proximal tibial fractures by their capability of providing axial and lateral compression. Chin et al reported functional outcomes of good to excellent $38.9 \%$ and fair in $61.1 \%$ of patients in his case series of Schatzker type $\mathrm{V}$ and $\mathrm{VI}$ tibial plateu fractures ${ }^{20}$. Catagni et al carried out a study on tibial plateau fractures treated with ilizarov ring fixator plus minimal internal fixation and results reported were excellent in 30 (50.85\%) and good in 27 (45.76\%) patients respectively. ${ }^{21}$

The Canadian Orthopaedic Trauma Association compared the outcomes of internal versus external fixation of Schatzker type $\mathrm{V}$ and $\mathrm{VI}$ tibial fractures in their randomized clinical trial of 83 patients and interpretation of better functional outcomes in terms of HSS scale external fixation group at 6 months and similar outcomes at 2 years follow up was made. ${ }^{22}$ In an another study by Katsenis et al excellent to good clinical results in $76 \%$ of patients whose tibial plateu fractures were treated with minimal internal fixation augmented by small wire external fixation frames. ${ }^{23}$ Excellent functional outcome in $54 \%$ of patients and radiological outcome in tems of mean union time of 13.5 weeks shows that hybrid fixator is well tolerated by most of patient.Our results are consistent with previous studies supporting hydrid fixator as suitable fixation option in Schatker type V and VI tibial plateau fracture aside plating.

\section{CONCLUSION}

We have found that hybrid external fixator is a reliable method of fixation of complex tibial plateau fractures apart from plating. With good functional and radiological outcome, lower rate of infection and early mobilization, it can be used as a preferred mode of treatment in high energy proximal tibial fractures where soft tissue envelope is compromised and also in open fractures.

\section{REFERENCES}

1. Hohl M. Fractures of the proximal tibia and fibula. In: Rockwood CGD, Bucyholz R, editors. Fractures in adult. Philadelphia: JB Lippincott; 1992;p. 1725-57.

2. Eggli S, Hartel MJ, MD S, Haupt U, Exadaktylos AK, Roder C Unstable Bicondylar Tibial Plateau Fractures: A Clinical Investigation. J Orthop Trauma 2008;22:673-679.
3. Schatzker J: Fractures of the tibial plateau.Edited by: Schatzker J, Tile M. The Rationale of Operative Orthopaedic Care, Springer-Verlag, New York;1988;279-295.

4. Hackl W, Riedl J, Reichkendler M, Benedetto KP, Freund M, Bale R Preoperative computerized tomography diagnosis of fractures of the tibial plateau. Unfallchirurg 2001:104:519-523.

5. Barei DP, Nork SE, Mills WJ, Henley MB, Benirschke SK. Complications AssociatedWith Internal Fixation of High-Energy Bicondylar Tibial Plateau Fractures Utilizing a two-Incision technique. J Orthop Trauma 2004;18:649-657.

6. Mallik AR, Coval DJ, Whitelaw GP: Internal versus external fixation of bicondylar tibial plateau fractures. Orthop Rev 1992;21:1433-1436.

7. Babis GC, Evangelopoulos DS, Kontovazenitis P, Nikolopoulos K, Soucacos PN. High energy tibial plateau fractures treated with hybrid external fixation. J Orthop Surg Res. 2011;14;6:35.

8. Murphy CP, D'Ambrosia R, Dabezies EJ. The small pin circular fixator for proximal tibial fractures with soft tissue compromise. Orthopedics 1991;14:273-280.

9. Babis et al. High energy tibial plateau fractures treated with hybrid external fixation. J Orthop Surg Res. 2011 6:35.

10. Delamarter RB, Hohl M, Hopp E. Ligament injuries associated with tibial plateau fractures. Clin Orthop Relat Res 1990;250:226-233.

11. Reichard AK, Seligson D, Alt V. External fixation of tibial plateau fractures: a retrospective evaluation and case report. Osteo Trauma Care. 2004;12:33-36.

12. Weiner LS, Kelley M, Yang E, Steuer J, Watnick N, Evans M, Bergman $M$ : The use of combination internal fixation and hybrid external fixation in severe proximal tibial fractures. J Orthop Trauma 1995, 9:244-250.

13. Watson JT, Coufal C. Treatment of complex lateral plateau fractures using Ilizarov techniques. Clin Orthop Relat Res 1998;353:97-106.

14. Tscherne $\mathrm{H}$, Obenhofferm P. Tibia1 plateaufractures. Management and expected results. Clin Orthop Relat Res. 1993;292:87-100.

15. Stevens DG, Beharry R, McKee MD, Waddell PJ, Schemitsch EH: The long term functional outcome of operatively treatedtibial plateau fractures. J Orthop Trauma 2001, 15:312-320.

16. Young MJ, Barrack RL. Complications of internal fixation of tibialplateau fractures. Orthop Rev. 1994;23:149-54.

17. Keogh P, Kelly C, Cashman WF, McGuinness AJ, O'Rourke SK. Percutaneous screw fixation of tibial plateau fractures. Injury 1992:23:387-389.

18. Jiang R, Luo CF, Wang MC, Yang TY, Zeng BF. A comparative study of Less Invasive Stabilization System (LISS) fixation and two-incision double plating for the treatment of bicondylar tibial plateau fractures. Knee. 2008;15:139-143.

19. Higgins TF, Klatt J, Bachus KN. Biomechanical analysis of bicondylar tibial plateau fixation: how does lateral locking plate fixation compare to dual plate fixation? J Orthop Trauma. 2007;21:301-306.

20. Chin TYP, Bardana D, Bailey M, Williamson OD, Miller R, Edwards ER, Esser MP. Functional outcome of tibial plateau fractures treated with the fine-wire fixator. Injury 2005;36:1467-1475.

21. Catagni MA, Ottaviani G, Maggioni M. Treatment strategies for complex fractures of the tibial plateau with external circular fixation and limited internal fixation. J Trauma. 2007;63:1043-1053.

22. Hall JA, Beuerlein MJ, McKee MD. Canadian Orthopaedic Trauma Society: Open reduction and internal fixation compared with circular fixator application for bicondylar tibial plateau fractures. Surgical technique. J Bone Joint Surg Am. 2009;91:74-88.

23. Katsenis D, Athanasiou V, Megas $P$, Tillianakis M, Lambiris E. Minimal internal fixation augmented by small wire transfixion frames for high energy tibial plateau fractures. J Orthop Trauma. 2005;19:241-248. 